\title{
LETTERS
}

\section{Systemic sclerosis following human cytomegalovirus infection}

\author{
C Ferri, M Cazzato, D Giuggioli, M Sebastiani, C Magro
}

Ann Rheum Dis 2002;61:937-938

S ystemic sclerosis (SSc) is a connective tissue disease characterised by skin and visceral organ involvement. ${ }^{12}$ The cause of SSc is still unknown; it has been suggested that one or more factors may be responsible for the disease through a complex pathogenic mechanism. ${ }^{34}$ Immune system dysregulation, collagen hyperproduction by altered fibroblasts, and vascular alterations can variably contribute to SSc development. The presence of Raynaud's phenomenon and diffuse microangiopathy suggests that endothelial injury may represent the first step in the pathogenesis of the disease. ${ }^{4}$ Numerous genetic, environmental, and infectious agents have been proposed as possible triggering factors. ${ }^{3-6}$ Among these, human cytomegalovirus (HCMV) infection may play a part in the pathogenesis of the SSc owing to its ability to infect both endothelial and monocyte/macrophage cells. ${ }^{67}$

Table 1 Clinicoserological features of the patient with SSc

\begin{tabular}{ll}
\hline Age/sex & $33 / \mathrm{F}$ \\
\hline Disease duration (years) & 2 \\
Skin sclerosis & + (hands, face) \\
Raynaud's phenomenon & + \\
Hypermelanosis & + \\
Calcinosis & - \\
Telangiectasias & + \\
Skin ulcers & + \\
Oesophageal involvement (x ray) & + \\
Lung fibrosis & + \\
Heart involvement & - \\
Kidney involvement & - \\
Nailfold capillaroscopy* & + \\
ANoA & + \\
Anti-HCMV & + (lgM type) \\
HCMV (ISH) & + \\
\hline
\end{tabular}

*SSc pattern: dilated capillaries and avascular areas. ANoA, anti-nucleolar antibodies; HCMV (ISH), human cytomegalovirus detected in the skin biopsy by in situ hybridisation technique (ISH).

\section{CASE REPORT}

Here, we describe the case of a 33 year old women developing SSc after a recent episode of acute HCMV infection. Her past medical history was unremarkable; of interest, the patient's mother was affected by systemic lupus erythematosus. Two months after an accidental exposure to sewer waters, the patient had a high fever, malaise, myalgias, lymphadenopathy, and a cutaneous rash. In February 2000 she was admitted to another hospital where she completely recovered within three weeks. At that time serum anti-HCMV antibodies of IgM isotype (Abbott Laboratories) were detected. Two months later, the patient developed weakness, polyarthralgias, Raynaud's phenomenon, and ischaemic lesions to the fingertips. In June 2000 she was first referred to our rheumatology unit, where a diagnosis of SSc was made based on the following findings: cutaneous hypermelanosis, sclerodactyly, puffy hands with pitting scars to fingertips, oesophageal dysmotility, mild interstitial lung disease, a scleroderma pattern at nailfold capillaroscopic examination (enlargement and loss of capillaries), and circulating antinuclear antibodies with antinucleolar pattern at indirect immunofluorescence on Hep2 cells (table 1). In addition, SSc was classified as the limited cutaneous variant according to currently accepted criteria. ${ }^{1}$ Virological investigations confirmed the presence of serum anti-HCMV antibodies, IgM type, followed one month later by seroconversion (anti-HCMV, IgG type). Moreover, the presence of HCMV RNA was demonstrated by an in situ hybridisation technique in the skin biopsy specimen, showing nuclear and cytoplasmic endothelial cell and eccrine ductular cell localisation (fig l).

During the two year follow up the patient's clinical condition progressively worsened because of recurrent skin ulcers at the fingers, partly responsive to prostacyclin analogue (iloprost) infusion treatment.

\section{DISCUSSION}

This is the first observation of SSc following recent HCMV infection. The appearance of SSc shortly after an acute episode of viral infection suggests a possible triggering role for HCMV.

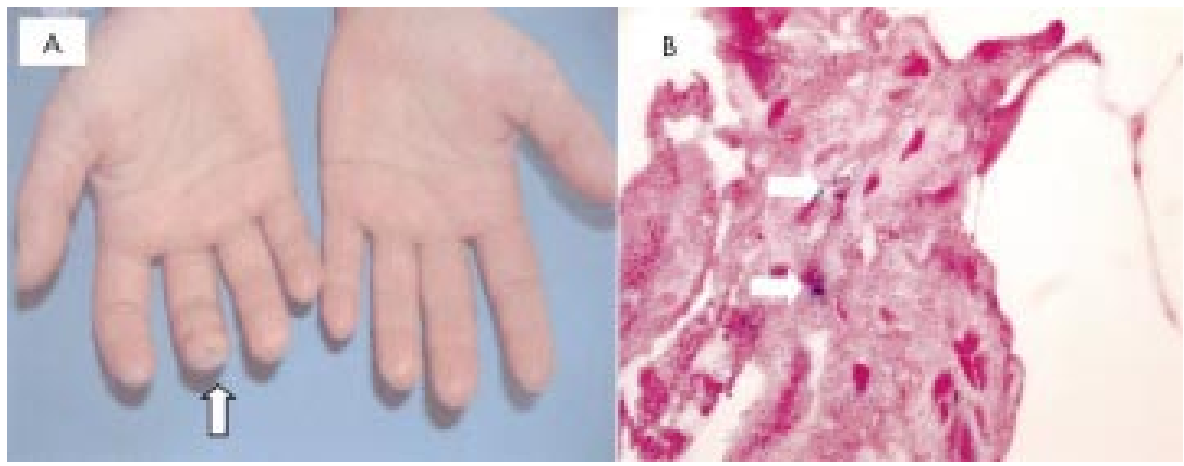

Figure 1 (A) Sclerodactyly and skin ulcer in the third fingertip of the right hand (arrow); (B) skin biopsy: reverse transcriptase-polymerase chain reaction in situ for HCMV RNA showing granular nuclear staining of endothelial cells (arrows). 
The presence of HCMV sequences within endothelial and epithelial cells may be responsible for viral lytic effect, directly and/or through HCMV driven autoimmune reaction. ${ }^{6-9} \mathrm{Circu}-$ lating IgG autoantibodies which can bind the HCMV late protein UL94 and induce apoptosis of endothelial cells have been recently demonstrated in patients with SSc. ${ }^{10}$ The HCMV seems to be able to trigger a host antiviral response responsible for specific autoantibodies cross reacting with endothelial autoantigens. ${ }^{10}$ This molecular mimicry mechanism had been also suggested for different disorders characterised by diffuse vascular disease, including SSc. ${ }^{7}$ The HCMV driven autoimmunity may be crucial in the cascade of events leading to typical SSc alterations-namely, endothelial cell injury and consequent up regulation of fibrogenic cytokines. A possible contribution of other cofactors, ${ }^{1-4}$ can also be taken in account; among these, the familial predisposition to autoimmune disorders, as seen in our patient.

\section{Authors' affiliations}

C Ferri, M Cazzato, D Giuggioli, M Sebastiani, Department of Internal Medicine, Rheumatology Unit, University of Pisa, Pisa ltaly

C Magro, Ohio State University Medical Center, Columbus, OH, USA

Correspondence to: Professor C Ferri, Dipartimento Medicina Interna, Reumatologia, Via Roma 67, 56126 Pisa, Italy; c.ferri@int.med.unipi.it

\section{REFERENCES}

1 LeRoy EC, Black C, Fleischmajer R, Jablonska S, Krieg T, Medsger TA Jr, et al. Scleroderma (systemic sclerosis): classification, subsets and pathogenesis. J Rheumatol 1988;15:202-5.

2 Ferri C, Valentini G, Cozzi F, Sebastiani M, Michelassi C, La Montagna G. Systemic sclerosis: demographic, clinical, and serological features and survival in 1012 patients. Medicine (Baltimore) 2002;81:139-53.

3 White B. Immunopathogenesis of systemic sclerosis. Rheum Dis Clin North Am 1996:22:695-708.

4 LeRoy EC. Systemic sclerosis. A vascular perspective. Rheum Dis Clin North Am 1996;22:675-94

5 Ferri C, Giuggioli D, Sebastiani M, Zakrzewska K, Azzi A, Panfilo S, ef al. Parvovirus B19 infection of cultured skin fibroblasts from systemic sclerosis patients. Arthritis Rheum (in press).

6 Vaughan JH, Shaw PX, Nguyen MD, Medsger TA Jr, Wright TM, Metcalf JS, et al. Evidence of activation of 2 herpesviruses, Epstein-Barr virus and cytomegalovirus, in systemic sclerosis and normal skins. J Rheumatol 2000;27:821-3.

7 Pandey JP, Leroy EC. Human cytomegalovirus and the vasaculopathies of autoimmune diseases (especially scleroderma), allograft rejection, and coronary restenosis. Arthritis Rheum 1998;41:10-15.

8 Neidhart M, Kuchen S, Distler O, Bruhlmann P, Michel BA, Gay RE, et al. Increased serum levels of antibodies against human cytomegalovirus and prevalence of autoantibodies in systemic sclerosis. Arthritis Rheum 1999;42:389-92.

9 Kahaleh MB, LeRoy EC. Autoimmunity and vascular involvement in systemic sclerosis (SSc). Autoimmunity 1999;31:195-214.

10 Lunardi C, Bason C, Navone R, Millo E, Damonte G, Corrocher R, et al. Systemic sclerosis immunoglobulin $G$ autoantibodies bind the human cytomegalovirus late protein UL94 and induce apoptosis in human endothelial cells. Nat Med 2000;6:1183-6.

\title{
A case of orbital myositis associated with rheumatoid arthritis
}

\author{
S Nabili, D W McCarey, B Browne, H A Capell
}

\section{CASE REPORT}

A 51 year old woman with a 34 year history of seropositive, erosive, nodular rheumatoid arthritis (RA) complained of non-specific headache and diplopia of insidious onset at a routine appointment with her ophthalmologist. Her RA was generally well controlled with sulfasalazine $2 \mathrm{~g}$ daily, which she had taken for four years. Other drugs were bendrofluazide $2.5 \mathrm{mg}$ and atenolol $50 \mathrm{mg}$ daily for hypertension along with hypromellose eye drops for dry eyes. She had no other medical history of note. She had previously been treated with intramuscular gold from 1977 until 1985 and with auranofin from 1987 until 1996.

Physical examination showed weakness of the right medial, lateral, and superior recti. The most likely cause was thought to be ocular nerve palsy, but a magnetic resonance (MR) scan of the orbits and brain was arranged to investigate further.

Six weeks later the patient's symptoms had deteriorated significantly such that she had diplopia in the primary position. There was now gross restriction of horizontal movements in the right eye (fig lA) with some evidence of slight proptosis. There was obvious conjunctival chemosis and particularly marked injection over the insertion of the medial rectus. Laboratory investigations showed mildly raised inflammatory markers with erythrocyte sedimentation rate 20 $\mathrm{mm} / \mathrm{lst} \mathrm{h}($ normal $<12)$ and $\mathrm{C}$ reactive protein $16 \mathrm{mg} / \mathrm{l}$ (normal $<10)$. Other routine biochemistry investigations were normal but the thyroxine level was borderline at $146 \mathrm{nmol} / \mathrm{l}$ (normal 55-144). She remained seropositive for rheumatoid factor and had a positive antinuclear antibody with a titre of $1 / 40$. This had been positive before initiation of sulfasalazine treatment.

The MR scan showed no intracranial abnormality, but there was gross enlargement of the belly of the right medial rectus

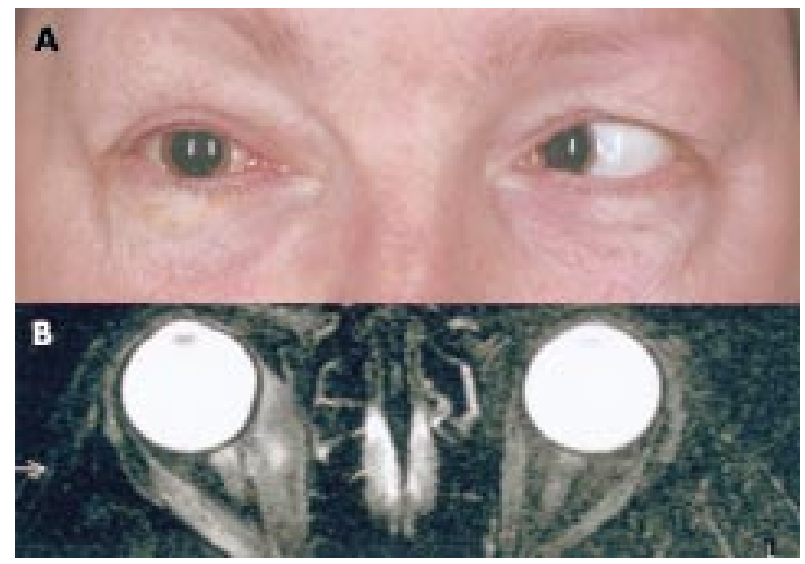

Figure 1 (A) The patient is asked to look to her right, demonstrating severe restriction of the right lateral rectus muscle. (B) $\mathrm{T}_{2}$ weighted magnetic resonance scan of the orbits before treatment. This shows gross thickening of the extraocular muscles with a high signal, indicating oedema. 
which measured $1 \mathrm{~cm}$ in diameter (fig $1 \mathrm{~B}$ ). There was less thickening of the other extraocular muscles. A high signal was seen in these muscles on $\mathrm{T}_{2}$ weighted imaging, indicating oedema and acute inflammation.

A diagnosis of orbital myositis (OM) was made and treatment was started with oral prednisolone $60 \mathrm{mg}$ daily. Her symptoms rapidly improved and steroid treatment was withdrawn within three months. Five months after her diagnosis she had mild restriction of horizontal movements in the right eye and repeat MR scan showed an element of chronic fibrosis.

\section{DISCUSSION}

OM is characterised by the onset of painful and limited extraocular movements, diplopia, ptosis, swelling of the lid, and localised chemosis and injection over the insertion of the inflamed muscle.

The most commonly affected muscles are the superior complexes and the medial rectus muscle. OM may attack more than one muscle, and may be bilateral or recurrent.

The major differential diagnosis is thyroid ophthalmopathy. However, dysthyroid myopathy is usually painless in onset, symmetrical, slowly progressive, and associated with systemic manifestations of Grave's disease. Lid retraction, limitation of the movement opposite to the affected muscle, and deterioration of visual function (colour vision, visual field, and visual acuity) may also occur in thyroid eye disease, in contrast with OM. Additional diseases that should be considered in the differential diagnosis include orbital cellulitis, metastasis, Tolosa-Hunt syndrome, trochleitis, and infectious myositis due to trichinosis. ${ }^{2}$

Imaging of the orbit in OM shows diffuse enlargement of the extraocular muscles, which exhibit slightly blurred margins.

Associations with OM include distant inflammatory disease such as Crohn's disease, ${ }^{3}$ Lyme disease, ${ }^{4}$ and Wegener's granulomatosis. ${ }^{5}$ It may also be a manifestation of a paraneoplastic syndrome. ${ }^{6}$ Although there are published reports of
OM associated with psoriatic arthropathy ${ }^{7}$ and systemic lupus erythematosus, ${ }^{89}$ there has only been one case reported in association with RA. ${ }^{10}$ Management is with corticosteroids and the rapid response is almost diagnostic.

Authors' affiliations

S Nabili, Ophthalmology Department, Gartnavel General Hospital, Glasgow, UK

D W McCarey, H A Capell, Centre for Rheumatic Diseases, Glasgow Royal Infirmary, Glasgow, UK

B Browne, Ophthalmology Department, Glasgow Royal Infirmary, Glasgow, UK

Correspondence to: Dr D W McCarey, Centre for Rheumatic Diseases, Glasgow Royal Infirmary, 84 Castle Street, Glasgow G4 OSF, UK; gcl376@clinmed.gla.ac.uk

Accepted 27 May 2002

\section{REFERENCES}

1 Berger JW, Rubin PA, Jakbiec FA. Pediatric orbital pseudotumor: case report and review of the literature. Int Ophthalmol Clin 1996:36:161-77.

2 Bouree P, Bouvier JB, Passeron J, Galanaud P, Dormont J. Outbreak of trichinosis near Paris. BM 1979;i:1047-9.

3 Dunro CA, Ehrlich R, Taylor R, Buncic JR, Hughes P, Griffiths AM. Keeping an eye on Crohn's disease: orbital myositis as the presenting symptom. Can J Gasteroentrol 1997; 1 1:497-500.

4 Seidenberg KB, Leib ML. Orbital myositis with Lyme disease. Am J Ophthalmol 1990;15:13-16.

5 Pinchoff BS, Sphalinger DA, Bergstrom TJ, Sandall GS. Extra ocular muscle involvement in Wegner's granulomatosis. J Clin Neurol Ophthalmol 1983:3:163-8.

6 Harris GJ, Murphy ML, Schmidt EW, Hanson GA, Dotson RM. Orbital myositis as a paraneoplastic syndrome. Arch Ophthalmol $1994 ; 112: 380-6$

7 Ajitsaria R, Dale R, Ferguson V, Mayou S, Cavanagh N. Psoriasis, psoriatic arthropathy and relapsing orbital myositis. Clin Exp Dermatol 2001;26:274-5

8 Grimson BS, Simons KB, Orbital inflammation, myositis, and systemic lupus erythematosus. Arch Ophthalmol 1983;101:736-8.

9 Serop S, Vianna RN, Delaey JJ. Orbital myositis secondary to systemic lupus erythematosus. Acta Ophthalmol 1994;72:520-3.

10 Panfilio CB, Hernandez-Cossio O, Hernandez-Fustes OJ. Orbital myositis and rheumatoid arthritis: case report. Arq Neuropsiquiatr 2000;58:174-7.

\section{Stiff man syndrome presenting with low back pain}

\section{A Bastin, V Gurmin, R Mediwake, J Gibbs, H Beynon}

S iff man syndrome (SMS) is a rare, disabling neurological disorder characterised by progressive muscle rigidity and painful episodic spasms of the axial and proximal limb muscles. Diagnosis is based on the recognition of typical clinical features and characteristic EMG findings. ${ }^{1}$ However, although it is well described, SMS is probably underdiagnosed because of a lack of awareness of its clinical manifestations. It may present to a range of specialties and should be considered in all patients with unexplained back pain, stiffness, and muscle spasms. We present a typical case of stiff man syndrome in a patient who was referred to our unit, having previously been seen by a number of doctors and a neurosurgeon, without a diagnosis.

\section{CASE REPORT}

A 42 year old man with a 28 year history of insulin dependent diabetes mellitus (IDDM) and a two year history of progressive pain and stiffness affecting his lower back and abdomen was seen in the rheumatology clinic. He also had painful, intermittent muscle spasms. His functional ability had significantly decreased and he complained of extreme difficulties in performing tasks requiring back flexion. Bladder and bowel function was normal. Blood sugars were controlled with insulin and he had no diabetic complications.

On examination, he had a marked lumbar lordosis, a prominent thoracic kyphosis, and a protuberant abdomen (fig 1). There was pronounced paraspinal and abdominal wall muscle rigidity. Neurological examination was otherwise normal. Blood tests showed a mildly raised haemoglobin $A_{\text {Ic }}$ (7.4) and plain radiography of the spine confirmed the clinical findings. The EMG was classical for SMS and showed sustained motor unit activity in agonist and antagonist axial and limb muscles, despite the patient's attempts at relaxation. The diagnosis was supported by the detection of antibodies against glutamic acid decarboxylase (GAD) in his serum. His condition only mildly improved with baclofen $80 \mathrm{mg} /$ day, and diazepam has now been introduced. 


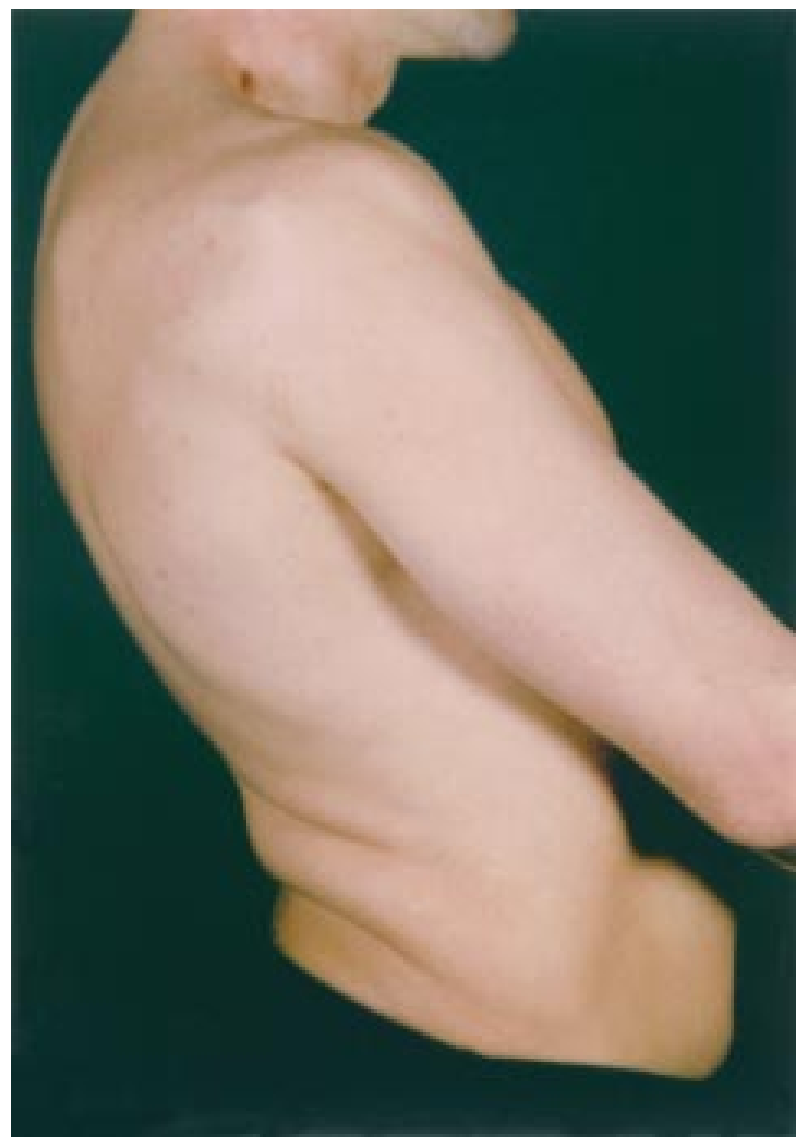

Figure 1 Patient with stiff man syndrome.

\section{DISCUSSION}

SMS has an insidious onset, usually in the fourth or fifth decades, with progressive muscle rigidity and episodic spasms affecting the axial and limb muscles. Muscle rigidity can lead to contractures, and simultaneous contraction of the thoracolumbar paraspinal and abdominal wall muscles causes lumbar hyperlordosis. Episodic muscle spasms are classical in SMS and their absence should raise suspicions about the accuracy of the diagnosis. ${ }^{1}$ The spasms, which are often provoked by emotional upset or sudden movement, can be extremely painful, generating forces capable of fracturing long bones. ${ }^{2}$ Rigidity and spasms gradually impair voluntary movements and postural reflexes, resulting in slow, restricted movements and an increased risk of falls. Intellect is not affected, and motor and sensory nerve examination is also normal. However, almost all patients have an abnormal EMG pattern, which shows continuous motor unit activity in affected muscles. ${ }^{1}$

The cause of SMS is unknown, but an autoimmune pathogenesis is suggested by the presence of autoantibodies and its strong association with autoimmune conditions, such as IDDM and thyroiditis. ${ }^{3}$ Antibodies against GAD are present in about $60 \%$ of patients with SMS. ${ }^{4}$ GAD is the rate limiting enzyme in the synthesis of $\gamma$-aminobutyric acid (GABA), one of the main inhibitory central neurotransmitters. Reductions in GABA production may therefore impair transmission at central nervous system inhibitory synapses, resulting in the continuous motor unit activity seen in this disease. Antibodies against amphiphysin, a nerve terminal protein, have been detected in up to $5 \%$ of anti-GAD negative patients. They are strongly associated with paraneoplastic SMS and their presence should prompt careful investigation to exclude malignancy, particularly breast cancer. ${ }^{5}$ However, approximately $40 \%$ of patients have no evidence of autoantibodies, suggesting that the pathogenesis of this syndrome may be heterogeneous. ${ }^{6}$

Drugs that enhance GABA-mediated central inhibition, such as diazepam (up to $300 \mathrm{mg} /$ day), baclofen, sodium valproate, and vigabatrin, are the mainstay of treatment for this previously refractory disease. Immunomodulatory treatments have also been used and favourable responses to corticosteroids, plasmapheresis, and intravenous immunoglobulin have been reported..$^{7-9}$ Physiotherapy is also important, offering a valuable adjunct to drug treatment.

SMS should be considered in all patients with unexplained back pain, stiffness and muscle spasms as early recognition and therapeutic intervention can significantly decrease morbidity and improve quality of life.

\section{Authors' affiliations}

A Bastin, V Gurmin, R Mediwake, H Beynon, Department of

Rheumatology, The Royal Free Hospital, Pond Street, London NW3 2QG, UK

J Gibbs, Department of Neurology, The Royal Free Hospital

Correspondence to: Dr H Beynon; hlcbeynon@aol.com

Accepted 15 March 2002

\section{REFERENCES}

1 Lorish TR, Thorsteinsson G, Howard FM. Stiff-man syndrome updated. Mayo Clin Proc 1989;64:629-36.

2 Layzer RB. Stiff-man syndrome -an autoimmune disease? N Engl J Med 1988:318:1060-2.

3 McEvoy KM. Stiff-man syndrome. Mayo Clin Proc 1991;66:300-4.

4 Solimena M, Folli F, Aparisi R, et al. Autoantibodies to GABAergic neurons and pancreatic beta cells in stiff-man syndrome. N Engl J Med 1990;322:1555-60

5 Folli $\mathbf{F}$, Solimena M, Cofiell R, et al. Autoantibodies to a 128-kd synaptic protein in three women with the stiff-man syndrome and breast cancer. $\mathrm{N}$ Engl J Med 1993;328:546-51

6 Grimaldi LME, Martino G, Braghi S, et al. Heterogeneity of autoantibodies in stiff-man syndrome. Ann Neurol 1993;34:57-64.

7 Piccolo G, Cosi V, Zandrini C, Moglia A. Steroid-responsive and dependent stiff-man syndrome: a clinical and electrophysiological study of two cases. Ital J Neurol Sci 1988;9;559-66.

8 Brashear R, Phillips HL II. Autoantibodies to GABAergic neurons and response to plasmapheresis in stiff-man syndrome. Neurology 1991:41:1588-92.

9 Barker RA, Marsden CD. Successful treatment of stiff man syndrome with intravenous immunoglobulin. J Neurol Neurosurg Psychiatry $1997 ; 62: 426-42$ 


\title{
A 26 week randomised, double blind, placebo controlled exploratory study of sulfasalazine in juvenile onset spondyloarthropathies
}

\author{
R Burgos-Vargas, J Vázquez-Mellado, C Pacheco-Tena, A Hernández-Garduño, \\ M V Goycochea-Robles
}

J uvenile onset spondyloarthropathies (SpA) comprise a group of conditions, characterised by recurrent episodes of arthritis and enthesitis that may lead to structural changes and functional impairment. ${ }^{1}$ Except for mild to moderate cases, the efficacy of non-steroidal anti-inflammatory drugs (NSAIDs) appears limited and glucocorticoids may induce severe adverse events. According to open trials, ${ }^{2-6}$ sulfasalazine (SSZ) appears to be a good alternative for treating juvenile onset SpA. Consequently, we conducted a phase III, exploratory, 26 week prospective, randomised, double blind, placebo controlled trial of SSZ in active juvenile SpA.

\section{PATIENTS AND METHODS}

Patients with the seronegative enthesopathy and arthropathy syndrome $(\mathrm{SEA})^{7}$ or ankylosing spondylitis (AS) ${ }^{8}$ (onset age 16 years; current age 20 years) fulfilling the three following criteria despite stable NSAID treatment in the previous four weeks were enrolled in the trial: $(a) \geqslant 4$ active joints; $(b) \geqslant 3$ tender entheses; and (c) erythrocyte sedimentation rate (ESR) $\geqslant 25 \mathrm{~mm} / \mathrm{lst} \mathrm{h}$. Exclusion criteria were diarrhoea, inflammatory bowel disease, mucositis, psoriasis, previous use of SSZ, sulphonamide or salicylates hypersensitivity, and concomitant diseases. The study was approved by the Institutional Review Board and parents and patients signed an informed consent.

Patient allocation into the group receiving SSZ or placebo was generated through a random number table; randomisation was restricted by blocks of four (ratio 1:1). Patients received identical tablets of $500 \mathrm{mg}$ enteric coated SSZ or placebo (Kabi-Pharmacia, Sweden) in numbered containers according to the next available number. Except for one of the investigators, all study personnel were unaware of the treatment assignment. Recruitment lasted 18 months.

Daily doses of SSZ and placebo escalated from two tablets in the first week and three in the second to four tablets in the third week. Children weighing less than $30 \mathrm{~kg}$ received 30-60 $\mathrm{mg} / \mathrm{kg} /$ day from the first to the third week.

Patients were allowed to continue receiving stable doses of NSAIDS or prednisone $(10 \mathrm{mg} /$ day) in the initial three months. NSAID dose change or prednisone addition to treatment qualified for lack of efficacy in the post hoc analysis. Paracetamol $(<\mathrm{lg} /$ day $)$, but no intra-articular or intralesional injections, was allowed for severe pain.

The number of active joints-defined by soft tissue swelling and tenderness when pressing or pain when moving the joints-was the primary outcome variable. Secondary variables included patient and doctor Likert scale assessments of efficacy (marked improvement or improvement, no change, or worsening) and health (very good, good, fair, or bad); pain severity on a $100 \mathrm{~mm}$ visual analogue scale; tender joints and entheses counts (excluding the tarsus); mid-foot swelling and tenderness; American College of Rheumatology functional class; ESR; anterior spinal flexion; and duration of morning stiffness. Clinical and laboratory examinations were performed monthly.

Data were analysed on the basis of the intention to treat principle. Baseline versus final values were analysed by paired $t$ test or Wilcoxon's signed rank, and SSZ versus placebo by $t$ test or Mann-Whitney test. The significance level was fixed at $\mathrm{p}<0.05$.

Thirty three patients (27 male, six female; mean age 15.9 (SD 3.9) years; 20 with SEA syndrome, 13 with AS) received

Table 1 Intragroup changes of selected outcome variables in the intention to treat analysis

\begin{tabular}{|c|c|c|c|c|c|c|}
\hline & \multicolumn{3}{|c|}{ Sulfasalazine $(n=17)$} & \multicolumn{3}{|c|}{ Placebo $(n=16)$} \\
\hline & Baseline & Final & $\mathrm{p}$ Value & Baseline & Final & $\mathrm{p}$ Value \\
\hline Active joints (count) & 3.9 (1.9) & $2.1(2.8)$ & 0.01 & $5.3(3.2)$ & $3.0(4.2)$ & 0.04 \\
\hline Tender entheses (count) & $7.3(5.6)$ & $4.7(5.6)$ & 0.007 & $9.3(4.8)$ & $4.8(5.7)$ & 0.004 \\
\hline Areas of foot tenderness (count) & $8.3(6.2)$ & $5.0(6.6)$ & 0.007 & $9.0(5.1)$ & $3.6(5.4)$ & 0.02 \\
\hline Areas of foot swelling (count) & $7.3(4.8)$ & $4.1(5.6)$ & 0.01 & $8.8(5.2)$ & $4.7(5.3)$ & 0.009 \\
\hline Pain VAS $(0-100 \mathrm{~mm})$ & $59.2(25.2)$ & $32.3(26.5)$ & 0.000 & $56.2(19.6)$ & $31.6(23.4)$ & 0.01 \\
\hline Morning stiffness (min) & $8.3(14.6)$ & $6.5(21.7)$ & 0.4 & $33.5(36.0)$ & $9.1(16.1)$ & 0.01 \\
\hline Anterior spinal flexion $(\mathrm{cm})$ & $5.5(1.3)$ & $6.2(1.4)$ & 0.03 & $5.4(2.4)$ & $5.7(2.6)$ & 0.1 \\
\hline Lumbar pain (No (\%) patients) & $5(29)$ & $1(6)$ & 0.18 & $8(50)$ & $3(19)$ & 0.137 \\
\hline Cervical pain (No (\%) patients) & $3(18)$ & 0 & 0.22 & $4(25)$ & $3(19)$ & 0.99 \\
\hline \multicolumn{7}{|c|}{ Physician efficacy assessment (No (\%) patients) * } \\
\hline Improved & \multicolumn{3}{|c|}{$10(59)$} & \multicolumn{3}{|c|}{$4(25)$} \\
\hline Unchanged & \multicolumn{3}{|c|}{$3(18)$} & \multicolumn{3}{|c|}{$10(63)$} \\
\hline Worsened & \multicolumn{3}{|c|}{$4(24)$} & \multicolumn{3}{|c|}{$2(13)$} \\
\hline \multicolumn{7}{|c|}{ Patient efficacy assessment (No (\%) patients) † } \\
\hline Improved & \multicolumn{3}{|c|}{$11(65)$} & \multicolumn{3}{|c|}{$4(25)$} \\
\hline Unchanged & \multicolumn{3}{|c|}{$2(12)$} & \multirow{2}{*}{\multicolumn{3}{|c|}{$7(44)$}} \\
\hline Worsened & \multicolumn{3}{|c|}{$4(24)$} & & & $5(31)$ \\
\hline
\end{tabular}


SSZ $(n=17)$ or placebo $(n=16)$. Two patients receiving SSZ and three receiving placebo were lost to follow up; treatment of two more receiving SSZ and eight receiving placebo was prematurely discontinued in the post hoc analysis because of lack of efficacy. The sample size has a post hoc statistical power of $11 \%$ for the number of active joints.

\section{RESULTS AND DISCUSSION}

Group characteristics-including the proportion with SEA syndrome and AS in each group-were comparable at baseline. Most variables in the SSZ and placebo groups improved significantly, but differences between groups were only significant in the doctor and patient assessments of improvement (table 1) and the number of changes of concomitant treatment $(2 v 8 ; \mathrm{p}=0.026)$. Four patients receiving SSZ and two receiving placebo had mild or moderate epigastric pain not requiring specific treatment or withdrawal from the study.

Although the lack of further differences between the groups may result from the small number of patients enrolled because of restrictions in the inclusion criteria, the high rate placebo response similar to that seen in adult onset SpA studies, ${ }^{9}{ }^{10}$ and additional factors, including the natural course of the disease, the results of this trial suggest that SSZ may be useful in active juvenile onset SpA.

\section{ACKNOWLEDGEMENT}

Supported (in part) by Kabi-Pharmacia, Sweden.

\section{Authors' affiliations}

R Burgos-Vargas, Research Division, Hospital General de Mexico J Vázquez-Mellado, C Pacheco-Tena, M V Goycochea-Robles, Rheumatology Service, Hospital General de Mexico
A Hernández-Garduño, Department of Clinical Research, Hospital General de Mexico

Correspondence to: Professor R Burgos-Vargas, Dirección de Investigación, Hospital General de Mexico, Dr Balmis 148, México DF 06726; burgosv@attglobal.net

Accepted 16 April 2002

\section{REFERENCES}

1 Burgos-Vargas R, Pacheco-Tena C, Vázquez-Mellado J. The juvenile onset spondyloarthropathies. Rheum Dis Clin North Am 1997;23:569-98

2 Mielants H, Veys EM. HLA-B27 related arthritis and bowel inflammation Part 1. Sulfasalazine (Salazopyrin) in HLA-B27 related reactive arthritis. J Rheumatol 1985; 12:287-293.

3 Joos R, Veys M, Mielants H, Von Werveke S, Goemaere S. Sulfasalazine treatment in juvenile chronic arthritis: an open study. J Rheumatol 1991;18:880-4

4 Suschke HJ. Treatment of juvenile spondyloarthritis and reactive arthritis with sulfasalazine. Monatsschr Kinderheilkd 1992;140:658-60.

5 Job-Deslandre C, Menkès CJ. Sulfasalazine treatment for juvenile spondyloarthropathy. Rev Rhum 1993;60:403-5.

6 Brooks CD. Sulfasalazine for the management of juvenile rheumatoid arthritis. J Rheumatol 2001;28:845-53.

7 Rosenberg AM, Petty RE. A syndrome of seronegative enthesopathy and arthropathy in children. Arthritis Rheum 1982;25:1041-7.

8 Bennett PH, Burch TA. New York symposium on population studies in the rheumatic diseases: new diagnostic criteria. Bull Rheum Dis $1967 ; 17: 453-8$.

9 Dougados $M$, van der Linden S, Leirisalo-Repo M, Huitfeldt B, Juhlin R, Veys $E$, et al. Sulfasalazine in the treatment of spondylarthropathy. A randomized, multicenter, double-blind, placebo-controlled study. Arthritis Rheum 1995;38:618-27.

10 Clegg DO, Reda DJ, Weisman MH, Blackburn WD, Cush JJ, Cannon $\mathrm{GW}$, et al. Comparison of sulfasalazine and placebo in the treatment of ankylosing spondylitis. A Department of Veterans Affairs Cooperative Study. Arthritis Rheum 1996;39:2004-12.

\section{Leflunomide decreases joint erosions and induces reparative changes in a patient with psoriatic arthritis}

\section{Cuchacovich, L Soto}

W e read with great interest the article by Scott and colleagues, ${ }^{1}$ in which they report radiological improvement or halting of disease progression with leflunomide treatment in a group of patients with rheumatoid arthritis (RA). Leflunomide has also been reported to be effective in some studies including a small group of patients with psoriatic arthritis (PsA), but radiological evolution was not evaluated. ${ }^{2}{ }^{3}$ We report the case of a patient with PsA who had clinical remission and radiological amelioration after a year with leflunomide treatment. To our knowledge, this is the first evidence that leflunomide may induce reparative changes such as filling of a bone cyst in a patient with PsA.

\section{CASE REPORT}

A 37 year old white man presented in August 1997 with a history of pain in the left wrist, right ankle, and both feet during the previous three months. His past history and physical examination were unremarkable except for synovitis in the painful joints and a single well demarcated erythematous hyperkeratotic plaque on the trunk. A dermatologist was consulted and psoriasis vulgaris was confirmed by biopsy.
No crystals were found in synovial fluid obtained from the right ankle. Hand and foot radiographs did not show osteoarticular damage. His rheumatoid factor was negative, haemoglobin, white cell blood count, and serum uric acid levels were normal; the erythrocyte sedimentation rate was 25 $\mathrm{mm} / \mathrm{lst} \mathrm{h}$. Meclofenamate $100 \mathrm{mg}$ three times a day was started, with good initial clinical response, and the dose was decreased to $100 \mathrm{mg}$ twice daily.

The patient remained stable until February 1998 when he consulted with recurrent joint symptoms. Marked pain and swelling was found in the previously affected joints. Sulfasalazine at a dose of $2 \mathrm{~g}$ /day was added to the meclofenamate, and the arthritis was controlled after two months of treatment. A new set of radiographs of the hands and feet did not show erosive changes.

He continued receiving the same treatment during the next 18 months, experiencing slight pain in both feet after climbing stairs or standing for long periods. In November 1999 he consulted with a new flare in the left wrist, right sacroiliac joint, and right foot. A new set of feet radiographs (fig lA) was obtained and showed erosions in the right fifth proximal interphalangeal joint and a subchondral cyst in the fifth metatarsal head. The left foot was radiologically normal. 


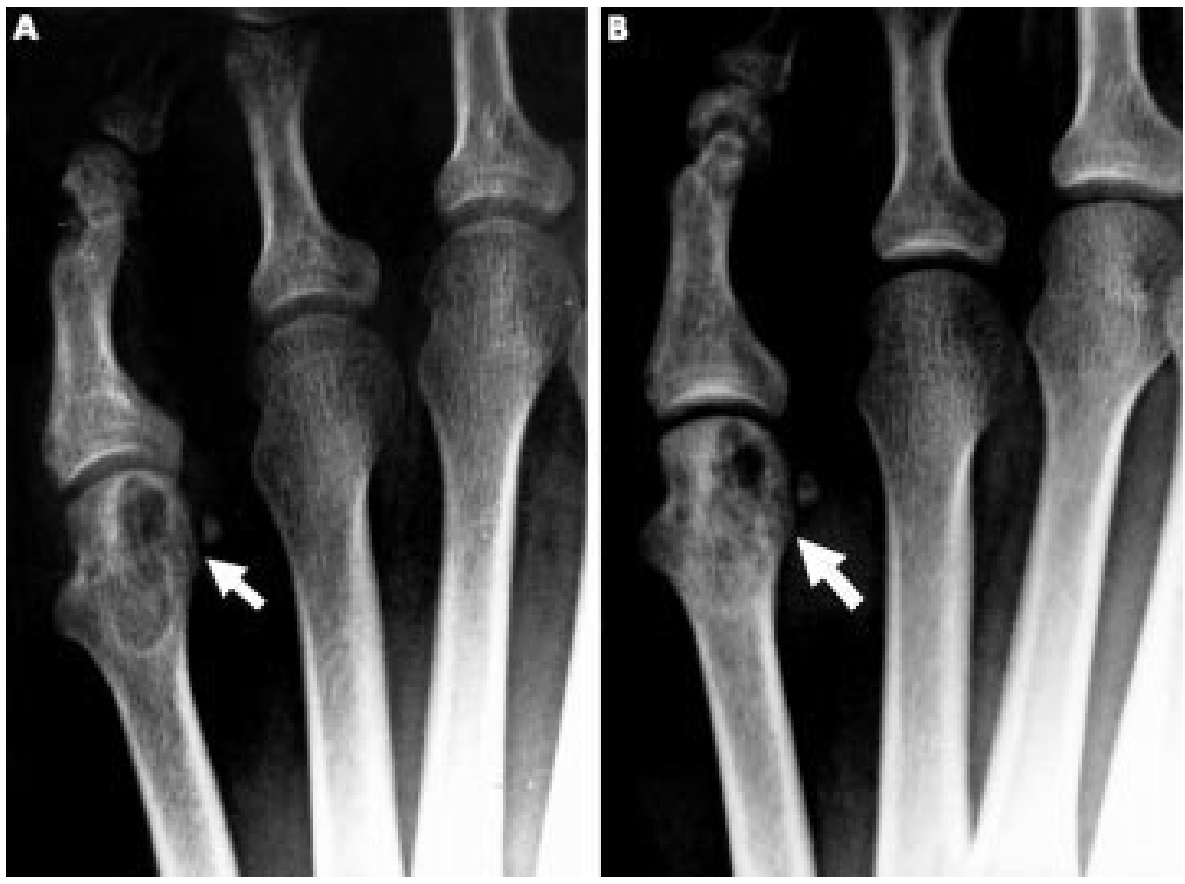

Figure 1 (A) November 1999. Active erosion in the right fifth proximal interphalangeal joint and a subchondral cyst in the fifth metatarsal head (arrow). (B) December 2000. Partial filling of the subchondral cyst, with nearly normal bone structure (arrow), progressive bone absorption of the erosion in the right fifth interphalangeal joint, and no new erosions. The metatarsophalangeal joint surface is regular, and the joint space is conserved.

Methotrexate was added to the treatment, but the patient developed fever and severe diarrhoea after the second dose. Methotrexate was stopped and leflunomide was started in January 2000. He received a three day initial loading dose of $100 \mathrm{mg} /$ day followed by $20 \mathrm{mg}$ daily doses.

With this new schedule the patient had clinical remission of the disease, and meclofenamate was changed to rofecoxib 25 $\mathrm{mg} /$ day.

A new set of radiographs (fig $1 \mathrm{~B}$ ) was performed a year later and showed partial filling of the subchondral cyst with bony sclerosis, progressive bone absorption of the erosion in the right fifth interphalangeal joint, and no new erosions.

At the present time the patient's disease remains inactive, but right foot pain appears after excessive mechanical stress.

\section{DISCUSSION}

Significant slowing of radiographic disease progression has been described, and reparative changes have been suggested with leflunomide treatment in patients with RA. ${ }^{1}$ However, up to now no radiological data are available for patients with PsA.

Our report describes a patient with PsA who developed an erosive disease despite being treated with other disease modifying antirheumatic drugs (DMARDs). After the addition of leflunomide to the treatment for more than one year, a bone cyst of a metatarsal head was seen to have filled.

The main objection for accepting the concept of "radiological joint amelioration" is that some authors argue that "filling in" of bone cysts, when presented in association with joint remodelling, may be an expression of disease progression and not a reparative process. ${ }^{4}$ However, in our patient filling of the bone cyst appeared without any evidence of remodelling in the distal articulating surface of the metatarsal head. The metatarsophalangeal joint surface is regular, and the joint space was conserved. In addition, no new erosions were detected.

There is both experimental and clinical evidence to show that reparative reactions occur in patients with RA treated effectively with DMARDs. ${ }^{5}$ It has also been reported that functional repairing of articular cartilage can occur if the proper environment is created to promote repair. ${ }^{6}$ Leflunomide limits $\mathrm{T}$ cell proliferation, enzymatic degradation of bone and cartilage by destructive metalloproteinases, and proinflammatory cytokines such as tumour necrosis factor $\alpha$, interleukin 1 , and interleukin $8 .^{7}$ These mechanisms may explain the prevention of structural damage seen with leflunomide in different studies.

In summary, we present radiological evidence that supports the hypothesis that leflunomide may induce reparative changes such as bone cyst filling in a patient with PsA. To confirm this finding it will be necessary to include radiographic scoring methods in future studies of leflunomide efficacy in PsA.

\section{Authors' affiliations}

M Cuchacovich, L Soto, Rheumatology Section, Department of Medicine, University of Chile Clinical Hospital, Santiago, Chile

Correspondence to: Dr M Cuchacovich, Roberto del Rio 978, Providencia, Santiago, Chile; mcuchaco@ns.hospital.uchile.cl

Accepted 6 March 2002

\section{REFERENCES}

1 Scott DL, Smolen JS, Kalden JR, van de Putte LBA, Larsen A, Kvien TK, et al. Treatment of active rheumatoid arthritis with leflunomide: two year follow up of a double blind, placebo controlled trial versus sulfasalazine. Ann Rheum Dis 2001;60:913-23.

2 Scali JJ, Visentini S, Salomón G, Castelli G, Barcena P, Morales E Treatment of psoriatic arthritis: open prospective study comparing efficacy and safety profile between leflunomide vs methotrexate [abstract]. Ann Rheum Dis 2000;59(suppl 1):POS-566.

3 Liang G, Barr W. Long term follow-up of the use of leflunomide in recalcitrant psoriatic arthritis and psoriasis [abstract]. Arthritis Rheum 2001;44(suppl):POS-413

4 Moeser PJ, Baer AN. Healing of joint erosions in rheumatoid arthritis [letter]. Arthritis Rheum 1990;33:151-2.

5 Rau R, Herborn G. Healing phenomena of erosive changes in rheumatoid arthritis patients undergoing disease-modifying antirheumatic drug therapy. Arthritis Rheum 1996;39:162-8.

6 Radin EL, Burr DB. Hypothesis: joints can heal. Semin Arthritis Rheum 1984; 13:293-302

7 Breedveldt FC, Dayer JM. Leflunomide: mode of action in the treatment of rheumatoid arthritis. Ann Rheum Dis 2000;59:841-9. 


\title{
Stress fracture of base of the acromion
}

\author{
N Roy, M G Smith, L G H Jacobs
}

Ann Rheum Dis 2002;61:944-945

F ractures of the scapula occur infrequently, with a fracture of the acromion being an even rarer entity. Acromial fractures constitute $9 \%$ of fractures of the scapula, which amounts to 3-5\% of shoulder girdle injuries. ${ }^{1}$ Fractures of the acromion are generally secondary to trauma, with only a few cases of stress fracture having been reported..$^{2-5}$

Reports published in English have described stress fractures of the acromion at the base of the acromion extending to the spine of the scapula, ${ }^{2}$ neck of the acromion, ${ }^{3}$ medial aspect of the acromion, ${ }^{4}$ and the base of the acromion only. ${ }^{5}$ These cases occurred in young to middle aged patients and were associated with a single violent muscle contraction or repetitive subcritical load to the shoulder. We present a case of an atraumatic osteoporotic stress fracture at the base of the acromion associated with chronic rotator cuff tear arthropathy.

\section{CASE REPORT}

The patient, an 82 year old woman, was admitted to the medical ward with heart failure and varicose ulcers. She was referred to the orthopaedic department because of a three day history of left shoulder pain without trauma. She was mostly wheelchair bound but did walk indoors with a Zimmer frame.

Examination showed mild tenderness and crepitus at the base of the acromion where a fracture gap could be palpated. Active shoulder movements were restricted to $90^{\circ}$ of both flexion and abduction. She also had a senile osteoporotic kyphosis of her thoracic spine. Anteroposterior and axillary radiographs of the shoulder showed a displaced fracture of the base of the acromion with superior subluxation of the head of the humerus, suggesting chronic rotator cuff tear arthropathy (figs 1 and 2). A radiograph of her spine confirmed the osteoporotic kyphosis of the thoracic vertebrae. Blood tests including full blood count, erythrocyte sedimentation rate (ESR), bone biochemistry, and myeloma screen were normal. She was treated conservatively in a broad arm sling with gradual mobilisation as her pain subsided. She recovered nearly full movements of her shoulder in four weeks. A follow up $x$ ray examination at six months showed a non-union of the fracture, which was not painful.

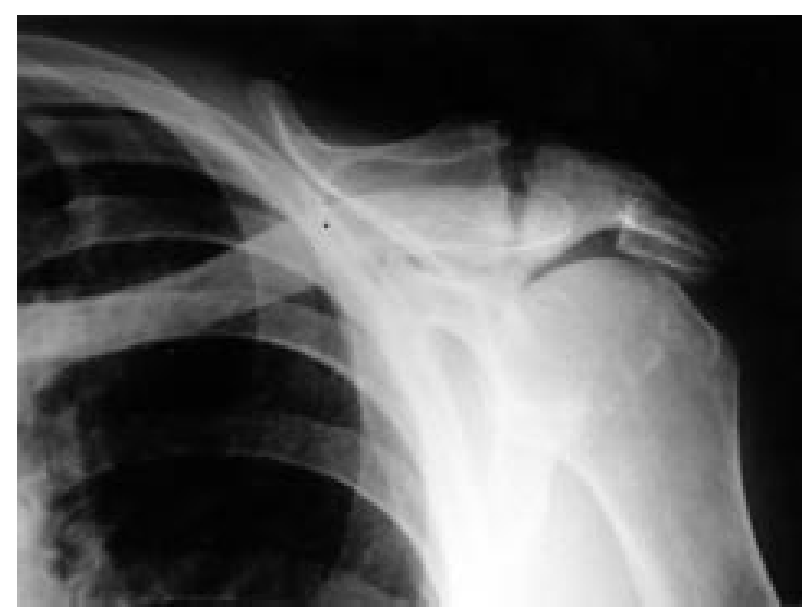

Figure 1 Anteroposterior view of the right shoulder showing fracture of the base of acromion.

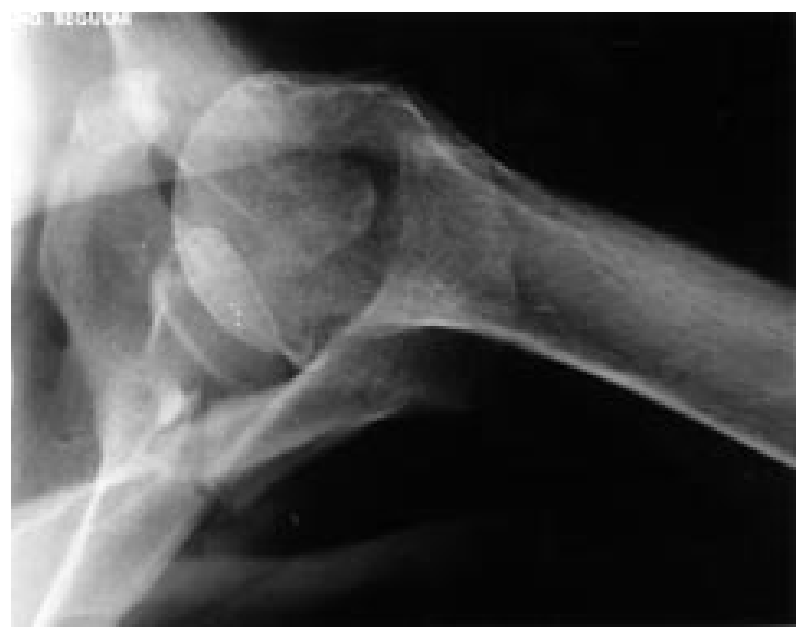

Figure 2 Axillary view of the right shoulder showing fracture of the base of the acromion.

\section{DISCUSSION}

Osteoporotic fractures without a history of trauma usually occur in the legs, pelvis or spine and rarely in the arms. Repetitive subcritical trauma or single violent muscular pulls have occasionally been associated with fractures of the acromion. ${ }^{1-5}$ Of the previous four cases of a similar type of injury reported, two were professional sports players, ${ }^{5}$ one was a car mechanic who felt a sudden crack in his shoulder while applying torque with a screwdriver, ${ }^{3}$ and the fourth was a woman playing golf, who suddenly felt acute pain in her shoulder as she hit the ball. ${ }^{2}$ It was not possible to correlate our patient's injury with any trauma, indeed she recalled waking up in the morning with sudden pain, which gradually got worse. Dennis et al reported three cases of stress fracture of the anterior impingement zone of the acromion. ${ }^{6}$ All three patients had severe rotator cuff arthropathy and two had steroid dependent rheumatoid arthritis. ${ }^{6}$ Surgical excision of the fragments was carried out in all three of his patients when conservative treatment had failed, with one patient eventually requiring shoulder replacement. Pain improved in the other two patients, but there was no improvement in the range of motion. All the fractures reported united after conservative treatment except in the series reported by Dennis et al. ${ }^{6}$

It is sometimes difficult to visualise this fracture without adequate penetration of radiographs in the appropriate plane. These fractures are best visualised in the axillary view in our opinion (fig 2). All previous cases have been either linear undisplaced fractures or diagnosed by an isotope bone scan. One case did show sclerosis at the base of the acromial arch on $x$ ray examination, which on subsequent bone scan was confirmed to be a fracture. ${ }^{5}$ We believe that abnormal pressure from the humeral head on the acromion, due to the rotator cuff arthropathy, leads to excessive movement at the fracture site causing a non-union of the fractured acromion.

Shoulder pain is a common complaint in elderly people. A stress fracture of the acromion should be considered in patients with chronic rotator cuff tear arthropathy who 
have osteoporosis and whose shoulder pain increases spontaneously. Routine use of good quality axillary radiographs in such patients should lead to a higher rate of diagnosis of such injuries.

\section{Authors' affiliations}

N Roy, M G Smith, L G H Jacobs, The Royal Oldham Hospital,

Rochdale Road, Oldham OL1 2JH, UK

Correspondence to: Mr M G Smith, Grove Cottage, 18 Grove Lane, Didsbury, M20 6UE, UK; mgsmith@doctors.org.uk

\section{REFERENCES}

1 Kuhn JE, Blaiser RB, Carpenter JE. Fracture of the acromion process: a proposed classification system. J Orthop Trauma 1994;8:6-13.

2 Hall RJ, Calvert PT. Stress fracture of the acromion: an unusual mechanism and review of the literature. J Bone Joint Surg Br 1995;77:153-4.

3 Rask MR, Steinberg LH. Fracture of the acromion caused by muscle forces. A case report. J Bone Joint Surg Am 1978; 60: 11 146-7.

4 Schils JP, Freed HA, Richmond BJ, Piraino DW, Bergfeld JA, Belhobek $\mathrm{GH}$.. Stress fracture of the acromion. AJR Am J Roentgenol 1990; 155:1140-1

5 Ward WG, Bergfeld JA, Carson WG. Stress fracture of the base of the acromion process. Am J Sports Med 1994;22:146-7.

6 Dennis DA, Ferlic DC, Clayton ML. Acromion stress fracture associated with rotator cuff arthropathy. A report of three cases. J Bone Joint Surg Am 1986;68:937-40.

\title{
$\alpha_{1}$ Antitrypsin deficiency in a patient with systemic vasculitis and primary Siögren's syndrome
}

\author{
F D Lindström, T Skogh, I M C Lundström
}

$\mathrm{T}$ he internal homoeostasis in man is critically dependent on regulation of proteolytic enzymes in tissues and fluids by endogenous inhibitors. $\alpha_{1}$ Antitrypsin is the most abundant protease inhibitor (Pi) in plasma, and controls tissue degradation by proteases such as trypsin, neutrophil elastase, and proteinase 3. ${ }^{1}$ Homozygous $\alpha_{1}$ antitrypsin deficiency is known to predispose to emphysema and chronic liver disease. ${ }^{23}$ Recently, a strong correlation has been found between systemic small vessel necrotising vasculitis and both heterozygous and homozygous $\alpha_{1}$ antitrypsin deficiency. ${ }^{4}$ Also, such deficiency has been found to confer a more disseminated disease and worse prognosis to patients with antineutrophil cytoplasmic antibody (ANCA) positive vasculitis. ${ }^{5}$

However, there is disagreement about the clinical implication of an intermediate $\alpha_{1}$ antitrypsin deficiency: is it an accidental finding or does it imply susceptibility to autoimmune disease? Thus, reports have demonstrated an increased incidence of $\alpha_{1}$ antitrypsin deficiency in patients with acute anterior uveitis, a finding that was refuted by others. ${ }^{6}$ Similarly, several reports have suggested an increased frequency of $\alpha_{1}$ antitrypsin deficiency in patients with rheumatoid arthritis, whereas others found no such association in similar patients.

\section{CASE REPORT}

Here, we report a severe vasculitic episode in a patient with primary Sjögren's syndrome (pSS) and heterozygous $\alpha_{1}$ antitrypsin deficiency.

The patient, a white woman, was diagnosed with pSS at the age of 44 years. The diagnosis fulfilled the Copenhagen and the European community classification criteria for $\mathrm{pSS} .{ }^{89}$ Five years after the start of sicca symptoms, arthritis suddenly appeared in the knee and ankle joints, as well as purpuric eruption on the lower legs. Laboratory studies showed a raised erythrocyte sedimentation rate (ESR $78 \mathrm{~mm} / \mathrm{lst} \mathrm{h}$ ) and $\mathrm{C}$ reactive protein (CRP $42 \mathrm{mg} / \mathrm{l}$; normal $<10 \mathrm{mg} / \mathrm{l}$ ) and on urine analysis proteinuria and microscopic haematuria. Oral prednisolone treatment was started, but a week later the patient suddenly experienced headache and loss of vision. Decreased wakefulness and generalised seizures ensued. Computed tomography of the brain showed three small haemorrhagic cortical infarctions, and an eye examination disclosed cortical blindness (complete visual loss with normal light reflexes). Two of three tests for circulating immune complexes were positive, and measurement of complement factors C3 and C4 showed relative deficiency of C4. $\mathrm{C} 4$ isotyping disclosed the phenotype C4A3B1. Positive serological tests (rheumatoid factor, antinuclear antibodies, and anti-SSA/SSB) were unchanged compared with before the acute episode, while an ANCA test and a test for antiphospholipid antibodies were negative.

Intravenous (IV) injection of methylprednisolone and bolus IV cyclophosphamide produced a rapid response and the arthritis disappeared and eyesight gradually improved. Urine findings and ESR/CRP normalised. Oral prednisolone and intermittent IV cyclophosphamide were given for one year.

A retrospective chart review has on two separate occasions shown low plasma levels of $\alpha_{1}$ antitrypsin $(0.7$ and $0.81 \mathrm{~g} / \mathrm{l}$, respectively; normal $0.9-1.7 \mathrm{~g} / \mathrm{l})$. Also, during the inflammatory episode, $\alpha_{1}$ antitrypsin levels remained normal, while other acute phase proteins were raised. Therefore a genetically determined heterozygous $\alpha_{1}$ antitrypsin deficiency was suspected . This was confirmed by $\alpha_{1}$ antitrypsin phenotyping using monoclonal antibody specific for the PiZ mutant in an enzyme linked immunosorbent assay (ELISA). ${ }^{10}$ Isoelectric focusing confirmed the PiMZ phenotype. ${ }^{11}$ The frequency of PiZ heterozygosity in the Swedish general population is 0.047 .

The diagnosis of vasculitis in this patient was not verified by biopsy, but the clinical evidence is compelling. The $\alpha_{1}$ antitrypsin deficiency in this patient is possibly related to the severe systemic vasculitis. Low levels of complement factor C4 have been reported in association with deficient elimination of circulating immune complexes in Sjögren's syndrome. ${ }^{12}$ In the present case the relative deficiency of $\mathrm{C} 4$, in addition to $\alpha_{1}$ antitrypsin deficiency, may hypothetically have contributed to an increased risk of immune complex mediated vasculitis.

\section{DISCUSSION}

The clinician should be observant about low levels of $\alpha_{1}$ antitrypsin in patients with vasculitis because they may indicate a poor prognosis. $\alpha_{1}$ Antitrypsin is an acute phase protein and therefore deficiency might be masked by the presence of inflammation. As in this case, normal $\alpha_{1}$ antitrypsin levels may be consistent with deficiency of the protein. For definite diagnosis it is essential to perform phenotype identification. ${ }^{11}$

\section{ACKNOWLEDGEMENT}

We thank Dr L Truedsson, Department of Microbiology, University Hospital, Lund, Sweden, for performing the C4 isotyping. 


\section{Authors' affiliations}

F D Lindström, T Skogh, Division of Rheumatology, Department of Molecular and Clinical Medicine, Faculty of Health Sciences, University Hospital, 58185 Linköping, Sweden

I M C Lundström, Department of Oral Medicine, University Hospital, 58185 Linköping, Sweden

Correspondence to: Dr F D Lindström; folke.lindstrom@swipnet.se

Accepted 4 March 2002

\section{REFERENCES}

1 Potempa J, Korzus E, Travis J. The serpin superfamily of proteinase inhibitors: structure, function and regulation. J Biol Chem 1994:269: 15957-60.

2 Eriksson S. Pulmonary emphysema and alfa-1-antitrypsin deficiency. Acta Med Scand 1964; 175:197-205

3 Carrell RW, Lomas DA. Alpha-1 antitrypsin deficiency - a model for conformational disease. N Engl J Med 2002;346:45-53.

4 Elzouki A-N, Segelmark M, Wieslander J, Eriksson S. Strong link between the alpha-1-antitrypsin PiZ allele and Wegener's granulomatosis. J Intern Med 1994;236:543-8.
5 Segelmark M, Elzouki A-N, Wieslander J, Eriksson S. The PiZ gene of alpha-1-antitrypsin as a determinant of outcome in PR3-ANCA positive vasculitis. Kidney Int 1995:48:844-50

6 Fearnley IR, Spalton DJ, Milford Ward A, Slavin B, Muncey F. Alpha-1-antitrypsin phenotypes in acute anterior uveitis. $\mathrm{Br} J$ Ophthalmo 1988;72:636-9.

7 Karsh J, Vergalla J, Anthony Jones E. Alpha-1-antitrypsin phenotypes in rheumatoid arthritis and systemic lupus erythematosus. Arthritis Rheum 1979:22:111-13.

8 Vitali C, Bombardieri S, Moutsopoulos HM, Coll J, Gerli R, Hatron PY, et al. Assessment of the European classification criteria for Siögren's syndrome in a series of clinically defined cases: results of a prospective multicentre study. Ann Rheum Dis 1996;55:116-21.

9 Manthorpe R, Oxholm P, Prause JU, Schiodt M. The Copenhagen criteria for Siögren's syndrome. Scand J Rheumatol 1986;15/suppl 61):19-21.

10 Wallmark A, Alm R, Eriksson S. Monoclonal antibody specific for the mutant $\mathrm{PiZ}$ alfa-1-antitrypsin and its application in an ELISA procedure for identification of PiZ gene carriers. Proc Natl Acad Sci USA 1984;81:5690-3

11 Jeppson JO, Frantzén B. Typing of genetic variants of alfa-1-antitrypsin by electrofocusing. Clin Chem 1982;28:219-22.

12 Hersey $P$, Lawrence S, Prendergast D Bindon C, BensonW, Valk P. Association of Siögren's syndrome with $\mathrm{C} 4$ deficiency, defective reticuloendothelial function and circulating immune complexes. Clin Exp Immunol 1983;52:551-60. 